\title{
Vivendo do outro lado do método canguru: a experiência materna ${ }^{1}$
}

\section{Living in the other side of kangaroo method: the mother's experience}

\author{
Viviendo en el otro lado del método canguro: la experiencia materna
}

\author{
Amanda Jesica Viana Santos Martins', Inês Maria Meneses dos Santos"
}

\section{RESUMO}

O presente trabalho tem por objetivos identificar as dificuldades enfrentadas pela mãe participante do Método Mãe Canguru e observar as estratégias por ela utilizadas neste procedimento para superá-las. Estudo descritivo de abordagem qualitativa, realizado em um hospital do município do Rio de Janeiro, no primeiro semestre de 2006. Os dados foram coletados mediante entrevista semi-estruturada com cinco mães internadas na enfermaria Canguru do referido hospital. A análise temática resultou em duas categorias: Aprendendo a ser Canguru e Vivendo como Canguru. Os resultados apontam que, muito embora as mães compreendam o valor do método para a recuperação de seus filhos, os dilemas e as dificuldades, particulares e de ordem familiar, podem comprometer e até impedir sua participação no programa. Desta forma, o apoio da família e da equipe de saúde é imprescindível para que a mãe consiga atuar no Canguru da melhor maneira possível.

Palavras chave: Enfermagem neonatal; Relações mãe-filho; Humanização da assistência.

\footnotetext{
ABSTRACT

The present research aims to identify the mother's difficulties to participate in the Kangaroo Mother Method, and to observe the strategies used by her in this method to overcome their difficulties. Descriptive study of qualitative approach performed in a hospital of the city of Rio de Janeiro, in the half first of 2006. The data were collected using a semistructured interview with five mothers at the Kangaroo ward of a hospital in Rio de Janeiro. The thematic analysis resulted in two categories: Learning how to be a Kangaroo, and Living as a Kangaroo. The results indicate that although the mothers acknowledge the method's importance for their children's recovery, the personal and familiar extent of their dilemma and adversities, can compromise, and even make them unable to participate in
}

the program. Therefore, the family and health team is crucial for the best participation of this mother in the Kangaroo Method.

Key words: Neonatal nursing; Mother-child relations; Humanization of assistance.

\section{RESUMEN}

Este estudio objetiva identificar las dificultades enfrentadas por la madre participante del Método Madre Canguro y observar las estrategias por ella utilizadas en este procedimiento para superar las dichas dificultades. Estudio descriptivo de abordaje cualitativa, realizado en un hospital de la ciudad de Río de Janeiro. Los datos fueron colectados mediante entrevista semiestructurada, la cual fue realizada con cinco madres internadas en la enfermería Canguro del hospital. El análisis temático resultó en dos categorías: Aprendiendo a ser Canguro y Viviendo como Canguro. Los resultados indican que, aunque las madres comprendan el valor del método para la recuperación de sus hijos, los dilemas y las dificultades, particulares 0 de nivel familiar, pueden comprometer y hasta mismo impedir su participación en el programa. De esta manera, el apoyo de la familia y del equipo de salud es imprescindible para que la madre consiga actuar en el Canguro de la mejor manera posible.

Palabras clave: Enfermería neonatal; Relaciones madre-hijo; Humanización de la atención.

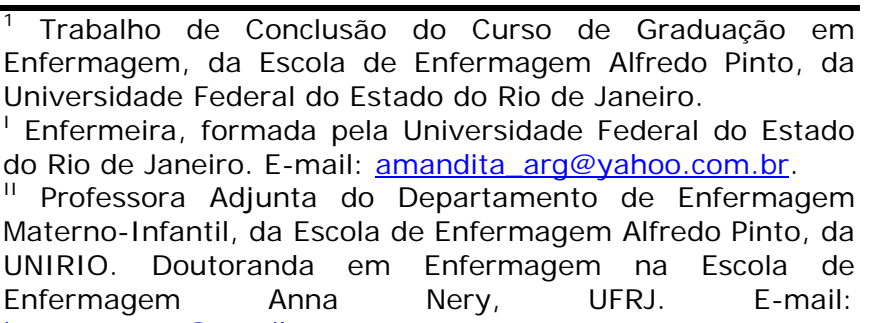
inesmeneses@gmail.com. 


\section{NTRODUÇÃO}

Nesta pesquisa trabalhou-se com a temática do Método Canguru (MC) também conhecido como "Cuidado Mãe Canguru" ou "Contato Pele a Pele", proposto como alternativa ao cuidado neonatal convencional para bebês de baixo peso ao nascer. Consiste em tecnologia de cuidado que proporciona uma transição suave para a vida extra-uterina e que tem na mãe uma figura indispensável nos cuidados e tratamentos do bebê(1).

É caracterizado recém-nascido de baixo peso ao nascer, todo bebê nascido com peso inferior a $2.500 \mathrm{~g}^{(2-3)}$, especialmente 0 prematuro ou pré-termo, que é considerado todo bebê nascido com menos de 37 semanas de gestação(2).

O MC introduziu um novo modelo de atenção ao implementar uma forma natural e humanizada de promover a adaptação e evolução desses bebês após o nascimento. Idealizado em 1979 por Edgar Rey Sanabria e Héctor Martínez Gómez, médicos do Instituto Médico Infantil (IMI) de Bogotá, Colômbia, é baseado em um programa cujo objetivo principal era a utilização do corpo da mãe como fonte de calor. A alternativa ao uso de incubadoras foi concebida porque os recursos materiais do país eram escassos. O nome do método foi adotado em referência às espécies cangurus marsupiais. As fêmeas deste grupo possuem uma bolsa onde as suas crias prematuras completam o tempo de gestação, sendo aquecidas e alimentadas até se fortalecerem e amadurecerem ${ }^{(1)}$.

A proposta do MC preconizou que, assim como os cangurus, as mães de bebês prematuros carregassem os seus filhos, quando os recém-nascidos tivessem condições clínicas, gástricas e respiratórias que viabilizassem uma situação estável. Os objetivos principais do método eram suprir a insuficiência de recursos materiais e evitar a separação prolongada entre a mãe e seu bebê $\hat{e}^{(1)}$.

Essa tecnologia de cuidado foi uma alternativa, ao método tradicional disponível e dispendioso de tratamento dos bebês prétermos, que eram assistidos e tratados em incubadoras. No MC, o contato íntimo do bebê com o corpo materno, ajudou na regulação da temperatura corporal da criança, na promoção do aleitamento materno e na diminuição da incidência de infecções hospitalares. Além disso, o MC propiciou o apego entre mãe e filho ${ }^{(1,3)}$.

O Cuidado Canguru, recentemente, passou a fazer parte das diretrizes políticas de atenção à saúde dos bebês de baixo peso ao nascer e prematuros, estando incluído no Programa de Humanização do Pré-Natal e Nascimento. Com a Portaria $n^{\circ} 693$, de 05 de julho de 2000, o Ministério da Saúde normatizou a implantação do Método MãeCanguru, definido no documento como assistência neonatal que implica no contato pele a pele precoce entre o binômio mãe-filho (recém-nascido de baixo peso, prematuro) ${ }^{(4)}$. Esse contato deve ocorrer de forma crescente, permitindo, dessa forma, maior participação dos pais no cuidado com seu filho. Os critérios de inclusão de um recém-nascido no $M C$ foram a estabilidade clínica e o ganho de peso ${ }^{(3-4)}$.

Diante do nascimento de um bebê prematuro, a literatura direcionava seu foco para as condições físicas e emocionais dos pais. Os dados existentes indicavam o grande estresse psicológico da família, em especial da mãe. Já a estratégia MC propicia, além do contato precoce pele a pele, a possibilidade de amamentar o filho e o resgate do processo difícil e estressante vivenciado diante da ocorrência de parto prematuro ${ }^{(3)}$.

Ao considerar a família, o MC ampliou a abordagem de cuidado para além do bebê de baixo peso, que geralmente era o centro da atenção da equipe de saúde neonatal. A família é uma organização social que pode ser afetada na sua estrutura em decorrência de diversos acontecimentos. O nascimento de uma criança, especialmente em situação de prematuridade, é um deles e pode acarretar mudanças profundas em suas rotinas e regras, que englobam relações internas e externas, bem como a vida no cotidiano $^{(5)}$.

Muitos estudos sobre o MC foram realizados, a maioria deles focando a perspectiva do bebê prematuro de baixo peso e abordando parâmetros anátomo-fisiológicos. Esses trabalhos buscaram comprovar os benefícios fisiológicos que o método proporcionou ao recém-nascido e compararam o desenvolvimento entre bebês Cangurus e bebês 
que não participaram do método, com intenção de verificar a eficácia do $M C^{(1,3)}$.

No entanto, com relação à perspectiva materna, a literatura é escassa e destaca o aumento da confiança materna conferido à mãe que cuida do filho à luz do método. Verificou-se, assim, uma lacuna em relação ao outro componente do método - a mãe -, já que esta técnica envolvia não apenas o recém-nascido, mas o binômio mãe-filho. Na maioria das vezes, os estudos versam apenas sobre os benefícios advindos do método, mas não se discute as dificuldades e limitações que essa mulher enfrenta para participar e desenvolver eficazmente o programa.

Além da constatação desses aspectos, a motivação dessa pesquisa floresceu também durante o ensino clínico na Atenção à Saúde do Recém-Nato, no sexto período da graduação em Enfermagem, onde se teve a oportunidade de presenciar a estratégia de assistência ao recém-nascido prematuro denominada Método Canguru (MC). Esta prática divergia do cuidado tradicional prestado ao prematuro, que não só submetia os bebês a longos períodos de internação em ambientes restritos e tecnificados, mas confinava os recém-nascidos às incubadoras. Esse procedimento tradicional tinha por justificativa a prevenção de infecções e a conseqüente melhoria das condições de sobrevivência. A conseqüência dessa prática, no entanto, adiava o estabelecimento do vínculo mãe/família - bebê e provocava o desmame precoce $^{(1,3)}$.

Já no MC, a mãe substitui gradualmente a incubadora e mantém o bebê aquecido por meio do contato com a sua pele. O MC preconiza que a criança fique em posição Canguru o maior tempo possível ${ }^{(3)}$. Na prática assistencial observou-se que era necessário, assim, que a mãe se reinternasse para acompanhar seu filho, "abandonando" sua casa, seu marido e filho(s) para dedicar-se exclusivamente a esse novo ser.

À luz da perspectiva da integralidade da assistência, é necessário ter sensibilidade para perceber que o tempo de internação materna pode ser relativamente prolongado e que a mulher não é um ser isolado do seu contexto social. É imprescindível assim, atenção aos aspectos técnicos da assistência, mas também abordagens que contemplem as particularidades de cada sujeito, especialmente no que diz respeito às questões sociais e pessoais dessa mulher $^{(6)}$.

Não se excluiu aqui, a necessidade de uma assistência de alta complexidade, prestada aos bebês prematuros e de baixo peso ao nascer. Mas, o processo natural, humano e simples viabilizado pelo MC, tem sido apontado como uma estratégia segura, eficaz e passível de ser implementado desde o nascimento. Isso pôde ser confirmado pela vivência e experiência do pessoal envolvido na atenção à mãe e ao bebê Canguru, assim como pelos estudos efetuados ${ }^{(5)}$.

Assim, esta pesquisa foi delineada tendo como objeto de estudo as estratégias maternas para participar do Método Canguru. Dessa forma, os objetivos do presente estudo foram identificar as dificuldades enfrentadas pela mãe participante do Método Canguru e observar as estratégias utilizadas pelas mães participantes do Método Canguru para superar as dificuldades.

\section{MÉTODO}

Estudo descritivo de abordagem qualitativa que prevê "uma ênfase sobre as qualidades das entidades e sobre os processos e os significados que não são examinados ou medidos em termos de quantidade, volume, intensidade ou freqüência"(7). $\mathrm{Na}$ pesquisa qualitativa, o pesquisador está interessado em descrever, por meio da palavra, sem reduzir os dados a meros números. Os dados são analisados indutivamente e o significado é crucial, pois o interesse do pesquisador é conhecer como pessoas dão sentido às suas vidas $^{(8)}$.

A investigação teve como cenário a enfermaria Canguru da Unidade Intermediária (UI), de um hospital público do município do Rio de Janeiro, contendo quatro leitos para o binômio.

Como forma de atender aos aspectos éticos e legais regidos pela Resolução 196/96 do Conselho Nacional de saúde, foi elaborado um documento solicitando permissão da realização da pesquisa ao hospital e ao Comitê de Ética da Secretaria Municipal de Saúde do 
Rio de Janeiro, aprovado sob o número do protocolo de pesquisa 34/06.

Utilizou-se um roteiro previamente estruturado com dados de identificação da mulher e do bebê, e mais cinco questões abertas que atendiam aos objetivos da pesquisa. As entrevistas foram realizadas após a assinatura do Termo de Consentimento Livre e Esclarecido. As entrevistas foram gravadas em fita magnética. As participantes foram identificadas pelo codinome mãe, seguido de uma numeração obedecendo à ordem em que foram entrevistadas. Dados de identificação do recém-nascido que a mãe não soube responder foram complementados com pesquisa no prontuário da criança. A coleta dos depoimentos ocorreu no primeiro semestre letivo de 2006.

Para o tratamento dos dados utilizou-se a análise temática, que "consiste em descobrir os núcleos de sentido que compõem uma comunicação cuja presença ou freqüência signifiquem alguma coisa para o objetivo analítico visado"(9). A construção das categorias de análise foi realizada a partir dos depoimentos, buscou-se por pontos de convergência na fala das entrevistadas para estabelecer as unidades temáticas, emergindo duas categorias: "aprendendo a ser Canguru" e "vivendo como Canguru".

\section{RESULTADOS E DISCUSSÃO}

$\mathrm{Na}$ instituição estudada, o MC era implementado após o nascimento do prematuro, na UTI ou na UI, assim que as condições clínicas da criança e da mãe permitissem, iniciando com contato pele a pele entre mãe e criança por um curto período, em adaptação (1 1 a etapa do $M^{(3)}$ ). Quando o recém-nascido encontrava-se na UI, estabilizado, podendo ficar com acompanhamento contínuo pela sua mãe; ambos aptos e desejosos em manter a posição Canguru, mãe e bebê eram transferidos para a enfermaria Canguru, com indicação da equipe de saúde ( 2 a etapa do $\mathrm{MC}^{(3)}$ ).

Neste estudo só foram entrevistadas mulheres que estavam realizando $O$ MC na enfermaria Canguru da UI, perfazendo um total de cinco. As entrevistadas tinham entre 17 e 34 anos de idade, sendo duas solteiras e três casadas. Apenas duas tinham outros filhos além dos bebês "cangurus". Para visualizar melhor a identificação das mães entrevistadas e a caracterização de seus filhos elaboraram-se os Quadros 1 e 2:

Quadro 1: Caracterização das Mulheres Entrevistadas em MC de hospital público do município do Rio de Janeiro, 2006

\begin{tabular}{ccccc}
\hline Entrevistada & I dade & Estado civil & Número de filhos & Tempo acompanhando o RN \\
\hline Mãe 1 & 34 & casada & 2 & 30 dias \\
Mãe 2 & 26 & solteira & 2 & 26 dias \\
Mãe 3 & 17 & solteira & 1 & 17 dias \\
Mãe 4 & 32 & casada & 1 & 11 dias \\
Mãe 5 & 32 & casada & 1 & 13 dias \\
\hline
\end{tabular}

Fonte: Enfermaria Canguru de uma Unidade Intermediária (UI) de um hospital público do município do Rio de J aneiro, 2006.

Quadro 2: Caracterização dos Filhos das Entrevistadas em MC de hospital público do município do Rio de Janeiro, 2006

\begin{tabular}{|c|c|c|c|c|c|c|}
\hline \multirow{2}{*}{$\begin{array}{l}\text { Filho } \\
\text { de }\end{array}$} & \multirow{2}{*}{$\begin{array}{l}\text { I dade gestacional } \\
\text { ao nascer }\end{array}$} & \multirow{2}{*}{$\begin{array}{l}\text { I dade cronológica na } \\
\text { época da entrevista }\end{array}$} & \multicolumn{2}{|c|}{ Tempo internação } & \multirow{2}{*}{$\begin{array}{l}\text { Peso ao } \\
\text { nascer }\end{array}$} & \multirow{2}{*}{$\begin{array}{l}\text { Peso } \\
\text { atual }\end{array}$} \\
\hline & & & UTI & UI & & \\
\hline Mãe 1 & 30 sem. & 30 dias & 21 dias & 9 dias & $1290 \mathrm{~g}$. & $1555 \mathrm{~g}$ \\
\hline Mãe 2 & 29 sem. & 26 dias & 12 dias & 14 dias & $1240 \mathrm{~g}$ & $1645 \mathrm{~g}$ \\
\hline Mãe 3 & 29 sem. & 17 dias & 9 dias & 8 dias & $1265 \mathrm{~g}$ & $1355 \mathrm{~g}$ \\
\hline Mãe 4 & 29 sem. & 27 dias & 14 dias & 13 dias & $1460 \mathrm{~g}$. & $1680 \mathrm{~g}$ \\
\hline Mãe 5 & 30 sem. & 13 dias & - & 13 dias & $1535 \mathrm{~g}$ & $1505 \mathrm{~g}$ \\
\hline
\end{tabular}

Fonte: Prontuários dos recém-nascidos hospitalizados em uma enfermaria Canguru de uma Unidade Intermediária (UI) de um hospital público do município do Rio de Janeiro, 2006.

Ao analisar os dados e se estabelecer as categorias "aprendendo a ser Canguru" e "vivendo como Canguru", observa-se que essas expressam as dificuldades enfrentadas por 
essas mães e a forma que elas encontraram para superar tais obstáculos e conseguir participar eficazmente do Método Canguru.

As falas das entrevistadas são apresentadas em itálico e utilizam a seguinte legenda: $\{\ldots\}$ pausa durante a fala $e[\ldots]$ recortes da fala.

\section{Aprendendo a ser Canguru}

Esta categoria emergiu a partir das dificuldades que foram identificadas nas falas das entrevistadas. Embora o hospital seja reconhecido pela implantação do método de acordo com as normas da portaria 693, do Ministério da Saúde ${ }^{(4)}$, verificou-se a necessidade de uma orientação mais efetiva e capaz de garantir, a essas mães, conhecimento mais amplo acerca do método e dos benefícios advindos dele.

Alguns depoimentos ilustraram bem a situação:

Me falaram mais ou menos o que era pra eu fazer $\{\ldots\}$ disseram que eu tinha de colocar ele no meu peito e ficar o máximo possível, essas coisas [...]. (Mãe 4)

Recebi umas explicações simples e bem básicas e apenas elas não foram suficientes pra eu participar direitinho do canguru, tanto que eu sempre tinha dúvidas e perguntava pra alguém. (Mãe 2)

Houve relatos de mães que foram iniciadas no método sem receber orientação:

Não recebi nenhuma orientação sobre o canguru, apenas chegaram pra mim e me avisaram que no dia seguinte eu ia pro canguru. (Mãe 1)

Eu nem sabia o que era esse negócio de canguru. A enfermeira simplesmente me disse que eu poderia colocar o meu neném no colo e que isso ajudaria ele a ganhar peso mais rápido e que ele não precisaria fazer força para ficar quentinho. (Mãe 3)

A partir destes depoimentos ficou evidenciado que as mulheres vão para a prática do MC com pouca orientação ou subsídio, encontrando assim dificuldades para desenvolver de forma adequada e efetiva o método. Aprenderam no dia-a-dia a se tornarem mães-Cangurus.

Ainda, dentro desta categoria, foram incluídas as dificuldades enfrentadas pelas mães relacionadas ao cuidado e manejo com o filho prematuro. Esses entraves foram ao encontro de estudos anteriores, segundo os quais, as mães dizem que o prematuro é diferente do filho de nove meses, uma vez que ele exige maiores cuidados, pois é pequeno, sensível, delicado e não recebe os cuidados maternos como um bebê a termo ${ }^{(1,3-4,10)}$.

A fala das entrevistadas indica as dificuldades:

No início eu tinha dificuldades pra pegar ele, porque ele é todo pequeninho, molinho $\{\ldots\}$ mas agora eu já perdi o medo. (Mãe 4)

Eu tenho feito tudo direitinho. O início pra mexer nele é que foi mais difícil, porque ele é todo pequeninho $\{\ldots\}$ mas agora eu já sei. (Mãe 3)

Foi de suma importância o papel que os profissionais de saúde ${ }^{(11-12)}$, e em especial a equipe de enfermagem ${ }^{(13)}$, desempenharam junto a essas mães como orientadores e facilitadores na prática do método, auxiliandoas na superação dos obstáculos encontrados durante sua vivência no MC na UI.

Eu senti mais dificuldades no início, tanto que eu pedia sempre pra enfermeira me ajudar, mas agora a insegurança já passou. (Mãe 2)

Pesquisa anterior comprovou que a aplicação do MC melhorou o estado de humor das mães Canguru, com relatos dessas se sentirem mais calmas, fortes, com idéias claras, ágeis, dinâmicas, satisfeitas, tranqüilas, perspicazes, relaxadas, atentas, competentes, alegres e amistosas $^{(14)}$.

Nos relatos analisados percebe-se que à medida que as mães passavam a se responsabilizarem pelo cuidado com o recémnascido, no decorrer da realização do Método Canguru, elas ficaram mais tranqüilas e melhoraram a qualidade do relacionamento mãe-filho. Esse relacionamento, possibilitado pelo Método Canguru, pôde ser entendido como uma forma de adequação e adaptação recíproca 
mãe-filho e como uma preparação para o cuidado em domicílio.

Percebeu-se por meio deste estudo, e de outros já realizados anteriormente, que a prática do Canguru contribuiu, de forma efetiva, para o aumento do senso de competência dos pais, atuando como capacitador para o cuidado desses prematuros em domicílio(10,15-18).

Os sentimentos de competência provem da participação da mãe Canguru no cuidado do bebê, ao passo que mães do método tradicional reportam maior dependência e sentimento de confiança nos equipamentos tecnológicos envolvidos no tratamento do pré-termo ${ }^{(14)}$.

\section{Vivendo como Canguru}

A experiência no $M C$ mostrou a intensa interferência nas relações familiares ${ }^{(19)}$. Observou-se que a ausência materna do domicílio alterou a dinâmica familiar, tanto no desempenho de papéis sociais como nas relações afetivas. O filho internado pode gerar desorganização familiar e isso ocorreu porque a mãe deixou suas atividades domésticas para permanecer com ele (recém-nascido), o que interferiu no cuidado dos outros membros familiares.

Meu marido às vezes fica um pouco estressado. Ele fala que eu não posso esquecer que eu tenho marido, outra filha, uma casa pra cuidar. Eu até entendo ele, porque eu estou praticamente um mês aqui direto. (Mãe 1)

A necessidade de cuidar de outros filhos pode ser um dos principais limitadores para a adesão ao MC. Esse fato é corroborado em pesquisa que analisou que as mães que optaram em participar do MC eram mais jovens, mais escolarizadas, sem outros filhos, recebiam mais ajuda nas tarefas domésticas e relataram menos dificuldades na amamentação(20).

Outra queixa formulada pelas mães entrevistadas disse respeito ao longo tempo de internação e a situação de estresse daí decorrente. Elas utilizaram variadas formas para aliviar a tensão e com isso deram continuidade ao Cuidado Canguru de forma eficaz.

O que é chato às vezes é o tempão que a gente tem que ficar no hospital. Às vezes parece que a gente fica meio perturbada de ficar tanto tempo dentro do hospital. Quando eu fico assim, eu pego e dou uma volta. (Mãe 3)

Às vezes bate um "estresse" sabe $\{. .$.$\} tem$ muito tempo que eu to aqui. Quando isso acontece eu ligo pra minha mãe e despejo tudo nela e fico mais aliviada. (Mãe 2)

A fala da mãe 2 demonstrou como é importante a participação da família para que elas conseguissem permanecer no hospital acompanhando seu filho. Foi fundamental que os demais familiares apoiassem essa mulher. Normalmente, são as mulheres que assumem as funções da mãe ausente no núcleo familiar: sua mãe, sogra, tias, irmãs e, às vezes, filhas mais velhas porque, culturalmente, são as mulheres que assumem o cuidado.

A tendência à conformação de famílias nucleares dificulta a participação das mulheres no $M C^{(20)}$. Mas, quando o parceiro se envolvia, acreditava no MC e a apoiava, os laços do núcleo familiar se fortaleceram, como relatou uma das mães:

Meu marido tem sido bastante compreensivo, me dando muita força. Ele vem me visitar e sempre me anima. (Mãe 4)

A despeito das dificuldades enfrentadas, essas mães priorizaram a saúde de seus filhos e abriram mão de suas necessidades para atender às de seus recém-nascidos, visando apenas a recuperação mais rápida deles.

Ouvi dizer que faz bem pro bebê e por isso eu aceitei ficar no canguru. Dizem que o bebê se recupera mais rápido ficando com a mãe o tempo todo. (Mãe 1)

Eu decidi participar porque faz bem pro meu bebê". (Mãe 4)

Acho que é importante pro meu bebê pegar peso. (Mãe 3)

A prematuridade, com seus riscos e conseqüências, tem um significado importante para os pais, e em resposta a essa condição colocam-se disponíveis para agir seguindo e aceitando as necessidades que a assistência impõe ${ }^{(19)}$.

A percepção da fragilidade do seu filho, uma das características do pré-termo, levou os 
pais a procurarem estratégias que favorecessem a recuperação e a sobrevivência do bebê. A primeira estratégia dos pais foi dar prioridade à criança, deixando tudo e fazendo o sacrifício necessário para lhe garantir a vida(5).

\section{CONSI DERAÇÕES FI NAIS}

O resultado deste estudo é uma contribuição a um tema que está em permanente transformação e, por isso, não se esgotou. Relataram-se as dificuldades que as mães encontraram na realização do Método Canguru, como elas se adequaram aos problemas enfrentados para buscar a superação dos obstáculos e a utilização deste instrumental da melhor forma possível.

Os medos, dúvidas e inseguranças quanto ao Método Canguru e ao manejo do recémnascido prematuro constituíram as principais dificuldades encontradas por essas mães. Porém, a prática do Canguru contribuiu para o aumento da competência materna no cuidado do seu filho.

O longo tempo de internação constituiu um fator estressante para essas mulheres. Por isso, o apoio da família foi imprescindível para que a mãe participasse do Canguru e pudesse suportar o afastamento do convívio familiar e de suas atividades cotidianas.

Para proporcionar os cuidados de enfermagem as mães Cangurus, na perspectiva da integralidade da assistência, é necessário, acima de tudo, sensibilidade para compreender que essas mulheres não são invisíveis. Elas estão inseridas em contextos sociais reais que impõem, de forma sutil ou não, as dificuldades da sua vivência.

Valorizar família parece ser o caminho adequado para o estudo da temática aqui proposta. Só assim, é possível enfocar a dinâmica interna das famílias Cangurus e compreender sua conduta diante da experiência vivenciada por um de seus membros - , no caso, da mãe e dos outros membros - , que, de forma cooperativa, ajustaram suas ações para resolver as dificuldades e promover a sustentação da coesão familiar mediante essa estratégia de cuidado.

\section{REFERÊNCI AS}

1. Charpak N, Calume ZF. O método mãecanguru: pais e familiares dos bebês prematuros podem substituir as incubadoras. Rio de Janeiro: McGraw Hill; 1999.

2. Ministério da Saúde; Secretaria de Assistência à Saúde, Coordenação MaternoInfantil. Manual de assistência ao recémnascido. Brasília (Brasil): Ministério da Saúde; 1994.

3. Ministério da Saúde; Secretaria de Políticas de Saúde, Área de Saúde da Criança. Atenção humanizada ao recém-nascido de baixo peso: método mãe-canguru: manual do curso. Brasília (Brasil): Ministério da Saúde; 2002.

4. Ministério da Saúde. Portaria no 693 de 5 de julho de 2000. Dispõe sobre norma de orientação para implantação do método canguru. Brasília (Brasil): Ministério da Saúde; 2000.

5. Caetano LC. Vivendo no método canguru: a tríade mãe-filho-família [tese]. [Ribeirão Preto]: Escola de Enfermagem de Ribeirão Preto/USP; 2004. $183 \mathrm{p}$.

6. Javorski M. Os significados do aleitamento materno para as mães de prematuros em cuidado canguru [dissertação]. [Ribeirão Preto]: Escola de Enfermagem de Ribeirão Preto/USP; 1997. $177 \mathrm{p}$.

7. Denzin NK, Lincoln YS. O planejamento da pesquisa qualitativa: teorias e abordagens. $2^{\underline{a}}$ edição. Porto Alegre: Artmed; 2006.

8. Gil AC. Como elaborar projetos de pesquisa. 4a edição. São Paulo: Atlas; 2002.

9. Minayo MCS. O desafio do conhecimento pesquisa qualitativa em saúde. 7ạ edição. São Paulo/Rio de Janeiro: HUCITEC/ABRASCO; 2000.

10. Cabral IE, Rodrigues EC. O método mãe canguru em uma maternidade do Rio de Janeiro 2000-2002: necessidades da criança e demanda de educação em saúde para os pais. Texto contexto-enferm. [Internet]. 2006 [cited 2008 mai 27];15(4):629-36. Available from: http://www. scielo.br/pdf/tce/v15n4/v15n4a11.pdf.

11. Lamy ZC, Gomes MAS, Gianini NOM, Hening MAS. Atenção humanizada ao recém-nascido de baixo peso - método canguru: a proposta brasileira. Ciênc. saúde coletiva [Internet]. 2005 [cited 2008 mai 27];10(3):659-68. 
Available

from:

http://www. scielo. br/pdf/csc/v10n3/a22v10n3.pdf.

12. Venancio SI, Almeida H. Método mãe canguru: aplicação no Brasil, evidências científicas e impacto sobre o aleitamento materno. J. Pediatr. [Internet]. 2004 [cited 2008 mai 27];80(5 suppl.):S173-80. Available from:

http://www.scielo.br/pdf/jped/v80n5s0/v80n5s 0a09.pdf.

13. Guimarães GP, Montecelli. A formação do apego pais/recém-nascido pré-termo e/ou de baixo peso no método mãe-canguru: uma contribuição da enfermagem. Texto contextoenferm. [Internet]. 2007 [cited 2008 mai 27]; 16(4):626-35. Available from: http://www. scielo.br/pdf/tce/v16n4/a06v16n4.pdf.

14. Cruvinel FG, Macedo EC. Interação mãebebê pré-termo e mudança no estado de humor: comparação do método mãe-canguru com visita na unidade de terapia intensiva neonatal. Rev. Bras. Saude Mater. Infant. [Internet]. 2007 [cited 2008 mai 27]; 7(4): 44955. Available from: http://www. scielo.br/pdf/rbsmi/v7n4/a12v7n4.pdf.

15. Bousso RS. Buscando preservar a integridade da unidade familiar: a família vivendo a experiência de ter um filho na UTI pediátrica [tese]. [São Paulo]: Escola de Enfermagem/USP; 1999. $191 \mathrm{p}$.

16. Duarte ED. "Agora eu me sinto como uma mãe de muito tempo": a mulher que realiza o cuidado mãe-canguru [dissertação]. [Belo Horizonte]: Escola de Enfermagem/UFMG; 2001. $142 \mathrm{p}$.

17. Furlan CEFB, Scochi CGS e Furtado MCC. Percepção dos pais sobre a vivência no método mãe-canguru. Rev Latino-am Enfermagem [Internet]. 2003 [cited 2008 mai 27]; 11(4):444-52. Available from: http://www. scielo.br/pdf/rlae/v11n4/v11n4a06.pdf.

18. Javorski M, Caetano LC, Vasconcelos MGL, Leite AM, Scochi CGS. As representações sociais do aleitamento materno para mãe de prematuros em unidade de cuidado canguru. Rev Latino-am Enfermagem [Internet]. 2004 [cited 2008 mai 27];12(6):890-8. Available from:

http://www. scielo.br/pdf/rlae/v12n6/v12n6a07.pdf.

19. Caetano LC, Scochi CGS, Angelo M. Vivendo no método canguru a tríade mãe-filho-família. Rev Latino-am Enfermagem [Internet]. 2005 [cited 2008 mai 27];13(4):562-8. Available from:

http://www.scielo. br/pdf/rlae/v13n4/v13n4a15.pdf. 20. Toma TS, Venâncio SI, Andretto DA. Percepção das mães sobre o cuidado do bebê de baixo peso antes e após implantação do método mãe-canguru em hospital público da cidade de São Paulo, Brasil. Rev. Bras. Saude Mater. Infant. [Internet]. 2007 [cited 2008 mai 27];7(3):297-307. Available from: http://www.scielo.br/pdf/rbsmi/v7n3/09.pdf.

Artigo recebido em 03.08.07

Aprovado para publicação em 30.09.08 